\title{
Prevalence and association of welding related systemic and respiratory symptoms in welders
}

\author{
M El-Zein, J-L Malo, C Infante-Rivard, D Gautrin
}

Occup Environ Med 2003;60:655-661

See end of article for authors' affiliations

Correspondence to:

Dr D Gautrin, Department of Chest Medicine, Sacré-Coeur Hospital, 5400 Gouin Blvd West, Montréal, Canada, H4J 1C5;

D-Gautrin@crhsc.umontreal.ca

Accepted 21 September 2002
Background: The prevalence of welding related respiratory symptoms coexisting with welding related systemic symptoms in welders is unknown.

Aims: To determine in a sample of welders the prevalence of coexisting welding related systemic symptoms indicative of metal fume fever (MFF) and welding related respiratory symptoms suggestive of occupational asthma $(\mathrm{OA})$, and the strength and significance of any association between these two groups of symptoms.

Methods: A respiratory symptoms questionnaire, a systemic symptoms questionnaire, and a questionnaire on occupational history were administered by telephone to 351 of a sample of 441 welders (79.6\%) from two cities in Québec, Canada.

Results: The co-occurrence of possible MFF (defined as having at least two symptoms of fever, feelings of flu, general malaise, chills, dry cough, metallic taste, and shortness of breath, occurring at the beginning of the working week, 3-10 hours after exposure to welding fumes) together with welding related respiratory symptoms suggestive of $\mathrm{OA}$ (defined as having at least two welding related symptoms of cough, wheezing, and chest tightness) was $5.8 \%$. These two groups of symptoms were significantly associated $\left(\chi^{2}=18.9, p<0.001\right)$.

Conclusion: There is a strong association between welding related MFF and welding related respiratory symptoms suggestive of OA. As such, MFF could be viewed as a pre-marker of welding related $\mathrm{OA}$, a hypothesis that requires further investigation.
W elders are workers at risk of developing respiratory symptoms and bronchial obstruction. This has been documented in several cross sectional studies. ${ }^{1}$ Cigarette smoking could also have an additive effect on these anomalies. ${ }^{2}$ Metal fume fever (MFF) remains the most frequently described systemic illness in welders. MFF is an occupationally acquired illness characterised chiefly by chills, fever, general malaise, and myalgia during or after a welding work shift. ${ }^{3}$ It is an acute systemic illness resulting from the inhalation of freshly formed metal oxide fumes from welding. ${ }^{5}$ Welding of galvanised steel is the most common cause of MFF. ${ }^{6}$

An estimated minimum of 1500-2000 cases of MFF occur each year in the United States. ${ }^{3}$ This is likely an underestimate of the actual incidence of MFF, as diagnosis can easily be overlooked due to the illness's mild influenza-like symptoms. MFF episodes were reported by over 35\% of 145 male welders from a West Coast shipyard during the Monday cross-shift as found by Kilburn and co-workers. ${ }^{6}$ Symptoms defining MFF included fatigue, headache, muscle aches, metallic taste, hoarseness, and sore throat. However, these authors did not make it clear how these symptoms were combined in calculat-

\section{Main messages}

- In a sample of 351 welders, the co-occurrence of metal fume fever with welding related respiratory symptoms suggestive of asthma approached $5 \%$.

- The association between metal fume fever and welding related respiratory symptoms suggestive of occupational asthma was significant, adjusting for smoking and physician diagnosed asthma.

- The prevalence of work related respiratory symptoms when welding on mild steel (almost $20 \%$ ) was similar to that when welding on galvanised steel $(18 \%)$. ing an index of MFF; thus their definition of MFF remains vague. As such, there is a need for characterising this syndrome along with carrying out a prevalence study of MFF.

MFF is said not to lead to serious sequelae, but until now this has not been adequately investigated. ${ }^{3}$ Very little is known about the long term effects of breathing metal fumes, and whether this systemic syndrome does resolve without inflicting any damage to the lung, or if prolonged exposure resulting in repeated episodes of MFF can enhance pulmonary impairment. Moreover, the frequencies of welding related respiratory symptoms suggestive of occupational asthma (OA) and welding related systemic symptoms in welders have not been previously explored, so that the prevalence of such respiratory symptoms coexisting with systemic symptoms is unknown. Furthermore, previous studies have examined the prevalence of MFF and of respiratory symptoms separately, while this survey has looked for the first time at the association between welding related MFF and respiratory symptoms.

The primary objectives of the study were to determine among a sample of welders: (1) the prevalence of welding related systemic symptoms suggestive of MFF; (2) the prevalence of welding related respiratory symptoms suggestive of $\mathrm{OA}$; and (3) the prevalence of these two groups of symptoms coexisting, and whether an association exists between them. The secondary objective was to explore the welding processes and the welded metals that are primarily associated with resulting respiratory and systemic symptoms.

Abbreviations: $\mathrm{Cl}$, confidence interval; FCAW, flux cored arc welding; GMAW, gas metal arc welding; GTAW, gas tungsten arc welding; MFF, metal fume fever; OA, occupational asthma; OAW, oxyacetylene welding; OR, odds ratio; SMAW, shielded metal arc welding 


\begin{tabular}{|c|c|c|}
\hline & $\mathrm{n}$ & $\%$ \\
\hline \multicolumn{3}{|l|}{ Age groups (years) } \\
\hline $20-34$ & 75 & 21.4 \\
\hline $35-44$ & 122 & 34.8 \\
\hline $45-54$ & 97 & 27.6 \\
\hline $55+$ & 57 & 16.2 \\
\hline Non-welding related asthma symptoms* & 94 & 26.8 \\
\hline Asthma† & 18 & 5.1 \\
\hline \multicolumn{3}{|l|}{ Smoking } \\
\hline Smokers & 253 & 72.1 \\
\hline Light smokers (<20 pack-years) & 152 & 60.1 \\
\hline Heavy smokers ( $\geqslant 20$ pack-years) & 101 & 39.9 \\
\hline Non-smokers & 98 & 27.9 \\
\hline \multicolumn{3}{|l|}{ Current job status } \\
\hline Active welders & 305 & 86.9 \\
\hline Retired welders & 46 & 13.1 \\
\hline \multicolumn{3}{|l|}{ Years of employment } \\
\hline $1-9$ & 64 & 18.2 \\
\hline $10-19$ & 116 & 33.1 \\
\hline $20-29$ & 91 & 25.9 \\
\hline $30+$ & 80 & 22.8 \\
\hline Age starting welding (years) & $21.8(5.5) \ddagger$ & $12-45 \S$ \\
\hline
\end{tabular}

*Presence of at least two positive answers to questions about: wheezing, chest tightness, shortness of breath or cough under usual conditions or under such conditions as exercise, exposure to cold air, strong odours, smoke, and dusts.

†Diagnosed by a physician as reported by welders. $\ddagger$ Mean (SD).

$\S$ Range.

\section{METHODS}

During the 1994-96 period, the Occupational Health Group from the Public Health Directorate of Montréal-Centre and Laval, Canada carried out a medical and/or environmental surveillance intervention programme in the manufacturing industries of primary metals, fabricated metal products, machinery, and transportation equipment, as well as the construction industry, where most welders in Canada are employed. In each industry, welders were classified to represent homogeneous exposure groups, from which a representative number of subjects were selected for the intervention by the hygienist in charge; this was carried out in industries from 15 economic sectors considered priority sectors by Quebec's Workers' Compensation Board (Commission de la Santé et de la Sécurité du Travail du Québec).

For the current survey, we used the available list of 441 welders involved in the intervention programme described above. This information included welders' names, addresses, phone numbers, and companies of employment. Sixty eight companies employing 1-5, 6-15, 16-50, or 51-100 employees were selected. We are therefore confident that our study subjects represent a reasonable though not random sample of welders employed in Quebec. Approval to obtain this information was given by the Commission d'accès à l'Information du Québec. This survey was approved by the ethics committee at the Sacré-Coeur Hospital.

Three different questionnaires (a respiratory symptom questionnaire, a systemic symptom questionnaire, and a questionnaire on occupational history) were administered by telephone, between September 1997 and April 1998.

The respiratory questionnaire was derived from the standardised questionnaire of the International Union against Tuberculosis and Lung Disease (IUATLD); it also included questions on smoking habits. ${ }^{7}$ This was followed by another original systemic symptom questionnaire adapted from a questionnaire developed by Menzies and colleagues ${ }^{8}$ to assess work related systemic symptoms considered typical of the "sick building syndrome". The principal elements of the systemic symptom questionnaire were chosen according to the clinical description of MFF. ${ }^{34}$ They included the following:
Table 2 Prevalence of welding related symptoms

\begin{tabular}{lrrl} 
& $\mathrm{n}$ & $\%$ & $95 \% \mathrm{Cl}$ \\
\hline Respiratory symptoms & 61 & 17.4 & 14.7 to 21.7 \\
$\quad$ Cough & 54 & 15.4 & 12.9 to 19.5 \\
$\quad$ Wheezing & 54 & 15.4 & 12.9 to 19.5 \\
$\quad$ Chest tightness & 12 & 3.4 & 2.0 to 5.4 \\
$\quad$ Others & 91 & 26.6 & 22.2 to 30.1 \\
$\quad$ At least one & & & \\
& 119 & 33.9 & 29.9 to 38.3 \\
Systemic symptoms & 149 & 42.5 & 37.6 to 46.5 \\
$\quad$ Flu-like symptoms & 183 & 52.1 & 47.5 to 56.4 \\
$\quad$ Aches and pains & 109 & 31.1 & 27.9 to 36.3 \\
$\quad$ Throat symptoms & 180 & 51.3 & 47.5 to 56.4 \\
$\quad$ Digestive symptoms & 134 & 38.2 & 33.7 to 42.4 \\
$\quad$ Taste symptoms & 294 & 83.8 & 80.5 to 87.1 \\
$\quad$ Fatigue symptoms & & & \\
$\quad$ At least one & 142 & 40.5 & 35.7 to 44.4 \\
$\quad$ Nasal symptoms (at least one) & & & \\
$\quad$ Ocular symptoms (at least one) & 187 & 53.3 & 49.5 to 58.4 \\
\hline
\end{tabular}

Table 3 Prevalence of symptoms* describing metal fume fever $(n=351)$

\begin{tabular}{|c|c|c|c|}
\hline & $n$ & $\%$ & $95 \% \mathrm{Cl}$ \\
\hline \multicolumn{4}{|l|}{ Flu-like symptoms } \\
\hline Fever & 46 & 13.1 & 11.1 to 17.4 \\
\hline Feelings of "flu" & 51 & 14.5 & 12.9 to 19.5 \\
\hline General malaise & 37 & 10.5 & 7.5 to 13.0 \\
\hline Chills & 52 & 14.8 & 12.9 to 19.5 \\
\hline \multicolumn{4}{|l|}{ Throat symptom } \\
\hline Dry cough & 107 & 30.5 & 26.0 to 34.2 \\
\hline \multicolumn{4}{|l|}{ Taste symptom } \\
\hline Metallic taste & 13 & 3.7 & 2.3 to 5.9 \\
\hline Shortness of breath & 156 & 44.4 & 39.6 to 48.5 \\
\hline
\end{tabular}

- History of a particular taste in the mouth (such as a sweet metallic taste)

- Flu-like symptoms (such as fever, feelings of flu, general malaise, chills )

- Myalgia, arthralgia, throat symptoms (such as dry, itchy, or constricted throat, dry cough, hoarseness )

- Digestive symptoms (such as loss of appetite, nausea, abdominal cramps)

- Fatigue (such as weakness, yawning, difficulty concentrating)

- History of respiratory symptoms (such as wheezing, chest tightness, shortness of breath, and cough).

For each of the above, information was also gathered on the timing of the occurrence of the symptoms' development and on their duration. The welding processes and the metals on which welding was performed when the symptoms occurred were documented.

This systemic symptom questionnaire was initially tested satisfactorily in a group of 10 welders with a clinical diagnosis of OA, some of whom had reported MFF.

These questions were followed by a third questionnaire on occupational history with the purpose of quantifying the number of years of experience in the welding profession.

As previously mentioned, there is no one available standardised definition of MFF in the literature. In the 
Table 4 Prevalence of welding related respiratory and systemic symptoms $(n=351)$

\begin{tabular}{|c|c|c|c|}
\hline & $\mathrm{n}$ & $\%$ & $95 \% \mathrm{Cl}$ \\
\hline \multicolumn{4}{|l|}{ Welding related respiratory symptom indices } \\
\hline Respiratory symptoms suggestive of asthma* & 50 & 14.6 & 12.9 to 19.5 \\
\hline Respiratory symptoms suggestive of asthma only at work $\dagger$ & 18 & 5.2 & 3.4 to 7.5 \\
\hline \multicolumn{4}{|l|}{ Welding related systemic symptom indices } \\
\hline Possible MFF & 69 & 19.7 & 16.6 to 23.8 \\
\hline Probable MFF§ & 42 & 12.0 & 9.3 to 15.2 \\
\hline \multicolumn{4}{|l|}{ Co-occurrence of MFF and respiratory symptoms } \\
\hline Possible MFF and respiratory symptoms suggestive of asthma & 20 & 5.8 & 3.9 to 8.2 \\
\hline Probable MFF and respiratory symptoms suggestive of asthma & 14 & 4.0 & 2.5 to 6.1 \\
\hline \multicolumn{4}{|c|}{$\begin{array}{l}\text { *Presence of at least two of the following welding related symptoms: cough, wheezing, and chest tightness. } \\
\text { †Presence of welding related asthma symptoms, excluding subjects with non-welding related asthma } \\
\text { symptoms. } \\
\text { †Having at least two of symptoms displayed in table } 3 \text {. } \\
\S \text { Having fever and at least two of: feelings of flu, general malaise, chills, metallic taste, shortness of breath, } \\
\text { and dry cough. }\end{array}$} \\
\hline
\end{tabular}

Table 5 Association between welding related respiratory symptoms and metal fume fever, duration of employment, smoking, and physician diagnosed asthma estimated by univariate logistic regression analysis

\begin{tabular}{|c|c|c|c|c|c|c|c|c|}
\hline & \multicolumn{2}{|c|}{ Cough } & \multicolumn{2}{|c|}{ Wheezing } & \multicolumn{2}{|c|}{ Chest tightness } & \multicolumn{2}{|c|}{$\begin{array}{l}\text { At least } 2 \text { respiratory } \\
\text { symptoms }\end{array}$} \\
\hline & OR & $95 \% \mathrm{Cl}$ & OR & $95 \% \mathrm{Cl}$ & OR & $95 \% \mathrm{Cl}$ & OR & $95 \% \mathrm{Cl}$ \\
\hline \multicolumn{9}{|l|}{ Models } \\
\hline 1. Possible MFF (n=69) & 3.20 & 1.74 to 5.86 & 4.33 & 2.31 to 8.12 & 4.42 & 2.35 to 8.30 & 3.97 & 2.06 to 7.63 \\
\hline \multicolumn{8}{|l|}{ 3. Employment (years) } & 1.98 to 8.71 \\
\hline 1-9 & 1 & - & 1 & - & 1 & - & 1 & - \\
\hline $10-19$ & 1.85 & 0.81 to 4.23 & 0.73 & 0.33 to 1.60 & 0.99 & 0.43 to 2.3 & 0.96 & 0.42 to 2.16 \\
\hline 20-29 & 0.85 & 0.33 to 2.19 & 0.38 & 0.15 to 0.99 & 0.88 & 0.36 to 2.16 & 0.47 & 0.18 to 1.24 \\
\hline $30+$ & 1.3 & 0.52 to 3.22 & 0.92 & 0.4 to 2.11 & 1.06 & 0.43 to 2.61 & 0.87 & 0.36 to 2.14 \\
\hline \multicolumn{9}{|l|}{ 4. Smoking } \\
\hline Non-smokers & 1 & - & 1 & - & 1 & - & 1 & - \\
\hline Light smokers* & 0.88 & 0.45 to 1.74 & 0.93 & 0.45 to 1.89 & 1.01 & 0.49 to 2.09 & 0.88 & 0.42 to 1.85 \\
\hline Heavy smokers** & 1.16 & 0.57 to 2.38 & 1.13 & 0.53 to 2.42 & 1.33 & 0.62 to 2.86 & 1.16 & 0.53 to 2.53 \\
\hline 5. Asthma $\dagger$ & 2.52 & 0.91 to 7.00 & 4.94 & 1.85 to 13.17 & 2.92 & 1.04 to 8.14 & 4.16 & 1.53 to 11.31 \\
\hline
\end{tabular}

Encyclopedia of Occupational Health and Safety, MFF is defined as a flu-like illness that develops after inhalation of metal fumes with symptoms beginning 3-10 hours after exposure. Initially, there may be a sweet metallic taste in the mouth accompanied by a worsening dry cough and shortness of breath. Fever and shaking chills often develop and the worker feels ill. Workers develop tachyphylaxis-that is, symptoms appear only when the exposure occurs after several days without exposure, not when there are regular repeated exposures. ${ }^{9}$

Based on this definition, two indices of MFF were defined:

(1) Possible MFF was defined as having at least two of the following symptoms: fever, feelings of flu, general malaise, chills, dry cough, metallic taste, and shortness of breath.

(2) Probable MFF was defined as having fever as a requisite, together with at least two of the following symptoms: feelings of flu, general malaise, chills, dry cough, metallic taste, and shortness of breath.

For these two indices, the individual symptoms were only considered when occurring at the beginning of the working week, 3-10 hours after exposure to welding fumes as reported by the welders.

The index of welding related respiratory symptoms suggestive of OA was defined as having at least two of the following symptoms: cough, wheezing, and chest tightness on exposure to welding fumes.

\section{Statistical analysis}

Frequency distributions were generated for welding related respiratory and welding related systemic symptoms as well as for the generated indices. $\chi^{2}$ analysis was used to test the association between respiratory symptoms and symptoms of MFF. Logistic regression analysis was performed, where odds ratios and $95 \%$ confidence intervals were estimated, examining the occurrence of respiratory symptoms associated with MFF, taking into account several potential risk factors, such as years of employment, smoking, and physician diagnosed asthma. Data summaries and statistical testing were performed using the SPSS statistical software package (SPSS, Inc., Chicago, IL). All statistical tests were two sided; a p value of 0.05 or less was adopted for statistical significance.

\section{RESULTS}

Data were obtained for 351 participants (as shown in table 1) out of 441 welders invited to participate in the study. This represented $79.6 \%$ of those eligible to be included in the study. From the available list of 441 workers, 18 were ineligible as they were not welders, 15 declined to participate in the study, and 57 were not reached, either because they could not be traced or because they had moved outside of the country. Of these 90 nonparticipants, information on age and gender was available for 69 male subjects with mean age of 41 (9.06) years.

At the time of the interview, 46 welders had already been retired for four years or less. Most of the welders were males 
Table 6 Association between MFF and welding related respiratory symptoms in multiple logistic regression analysis*

\begin{tabular}{|c|c|c|c|c|c|c|c|c|}
\hline & \multicolumn{2}{|c|}{ Cough } & \multicolumn{2}{|c|}{ Wheezing } & \multicolumn{2}{|c|}{ Chest tightness } & \multicolumn{2}{|c|}{ At least 2 respiratory symptoms } \\
\hline & OR & $95 \% \mathrm{Cl}$ & OR & $95 \% \mathrm{Cl}$ & OR & $95 \% \mathrm{Cl}$ & OR & $95 \% \mathrm{Cl}$ \\
\hline Possible MFF (n=69) & 3.40 & 1.83 to 6.33 & 5.06 & 2.61 to 9.81 & 4.83 & 2.53 to 9.22 & 4.57 & 2.31 to 9.05 \\
\hline Probable MFF $(n=42)$ & 4.59 & 2.22 to 9.47 & 4.61 & 2.16 to 9.85 & 5.45 & 2.58 to 11.52 & 4.88 & 2.24 to 10.63 \\
\hline
\end{tabular}

*The ORs for these models have been adjusted for years of employment, pack-years, and the presence of physician diagnosed asthma.

$(\mathrm{n}=350)$; they were between 20 and 71 years of age, with mean age of 43 (10.39) years. Twenty seven per cent of the study population had symptoms suggestive of non-welding related asthma and $5.1 \%$ reported having had asthma diagnosed by a physician (table 1). About one third of welders $(27.9 \%)$ had never smoked cigarettes, $38.5 \%$ were current smokers, and 33.6\%, ex-smokers. More than half of the population $(60.1 \%)$ were considered to be light smokers (smoking less than 20 pack-years), whereas $39.9 \%$ were heavy smokers (smoking more than 20 pack-years). The majority (86.9\%) still worked as welders; mean duration of employment as a welder was 20.33 (10.76) years at the time of the interview. The age at which welders had started their welding profession ranged from 12 to 45 years, with a mean of 22 (5.5) years. Most $(87.7 \%)$ had worked for five days a week as a welder and $97 \%$ reported welding for 40 or more hours per week. More than $65 \%$ of welders reported welding on stainless steel, mild steel, galvanised steel, and aluminium, and nearly half of them reported welding on various other metals as well.

As table 2 shows, $26.6 \%$ of welders reported experiencing at least one welding related respiratory symptom such as coughing, wheezing, chest tightness, or other respiratory symptoms. Only around $16 \%$ did not suffer from any systemic symptoms related to welding exposure such as flu-like symptoms, aches and pains, and throat, digestive, taste, and fatigue symptoms. On the other hand, about half of the welders experienced at least three of the above mentioned systemic symptoms while welding. The majority (89-97\%) of welders reported having the above mentioned systemic symptoms occurring 3-10 hours after exposure to welding fumes on a given day, and most (62-82\%) reported experiencing these symptoms at the beginning of the working week. In addition, a high percentage of the welders reported having at least one nasal (40.5\%) or ocular $(53.3 \%)$ symptom.

Table 3 displays the prevalence of signs and symptoms used in describing MFF. More than 10\% reported various flu-like symptoms, with a little less than half $(44.4 \%)$ experiencing shortness of breath. Around 30\% of welders reported dry cough, and only $3.7 \%$ described having a metallic taste in the mouth upon exposure to welding fumes.

Table 4 shows that around 15\% reported experiencing respiratory symptoms suggestive of $\mathrm{OA}$, and this figure decreased to $5 \%$ on exclusion of subjects with symptoms of non-welding related asthma. Possible MFF and probable MFF episodes were reported by $19.7 \%$ and $12 \%$, respectively. Also shown in this table is that fact that $5.8 \%$ and $4.0 \%$ of welders, respectively, stated the coexistence of possible MFF and probable MFF with two welding related respiratory symptoms.

Having at least two welding related respiratory symptoms suggestive of OA was significantly associated with possible MFF $\left(\chi^{2}=18.9, \mathrm{p}<0.001\right)$, as well as with probable MFF $\left(\chi^{2}=16.0, p<0.001\right)$. A significant association was found between the various individual symptoms used in defining MFF, except for metallic taste and respiratory symptoms (data not shown).

Table 5 shows that possible MFF and probable MFF appeared to be mostly associated with welding related respiratory symptoms suggestive of OA (at least two of cough, wheezing, and chest tightness). There was no significant increase in the risk of developing welding related respiratory symptoms with increasing categories of years of employment. Heavy smokers did not seem to be more at risk of developing welding related respiratory symptoms. As expected, the presence of physician diagnosed asthma as reported by the welders was found to be related to the presence of wheezing (OR $4.94,95 \%$ CI 1.85 to 13.7 ) and chest tightness (OR 2.92, 95\% CI 1.04 to 8.14 ).

As revealed by multiple logistic regression analyses (table 6), possible MFF and probable MFF remained significantly associated with welding related respiratory symptoms, even after adjusting for years of employment, pack-years, and the presence of physician diagnosed asthma.

Regarding the secondary objective of the study, the welding processes GMAW and SMAW, and the welded metals galvanised and mild steel were most closely associated with resulting respiratory and systemic symptoms describing MFF (see tables 7 and 8 ). These two welding processes were also most closely associated with nasal, ocular, throat, digestive, and fatigue symptoms. Galvanised and mild steel were also associated with the latter mentioned symptoms, as was stainless steel.

\section{DISCUSSION}

This descriptive study showed the co-occurrence of at least two welding related respiratory symptoms accompanying possible MFF and probable MFF to be $5.8 \%$ and $4 \%$, respectively. Although one may consider that an overlap between flu-like symptoms and respiratory symptoms could potentially confound the results, as they could frequently occur in the same individual during an episode of flu, welders reported the occurrence of these symptoms exclusively while performing welding operations in an attempt to exclude this possibility. The co-occurrence of respiratory symptoms and MFF has been previously reported in a few case reports. A case of acute reaction to zinc inhalation was reported by Malo and co-workers. ${ }^{10}$ This reaction comprised the classical signs and symptoms of MFF (fever, malaise, dyspnoea, leucocytosis) in addition to transient diffuse nodular infiltrates seen on chest $x$ ray examination (which is generally not the case in welder's fever) and evidence of temporary ventilatory impairment following a challenge test. This observation was supported by another report of a case that occurred during the melting of mainly copper, zinc, and aluminium for making shape memory alloys. Inhalation of the resulting fumes also led to a demonstrable transient respiratory impairment together with symptoms of MFF. ${ }^{11}$ Another case was reported, relating to pulmonary involvement in MFF, where a patient with a clinical history of recurring zinc fume fever underwent an experimental welding exposure. ${ }^{12}$ Pulmonary function tests showed a pronounced pulmonary reaction, and bronchoalveolar lavage, performed 24 hours after challenge, revealed a distinct increase of total cell count and the number of polymorphonuclear leucocytes.

It is known that welding can cause asthma as reported in several case reports and as reviewed. ${ }^{13}$ Exposure to metals (nickel, chromium, cobalt, etc) released during the welding process can be the cause of asthma. ${ }^{13}$ In our study, the prevalence of welding related respiratory symptoms suggestive of asthma, defined as the presence of at least two symptoms of 
Table 7 Prevalence of respiratory and systemic symptoms associated with various welding processes

\begin{tabular}{|c|c|c|c|c|c|c|c|c|c|c|c|c|c|c|c|c|c|c|}
\hline \multirow[b]{3}{*}{ Symptoms } & \multicolumn{18}{|c|}{ Welding processes } \\
\hline & \multicolumn{3}{|c|}{ SMAW* } & \multicolumn{3}{|c|}{ GMAW† } & \multicolumn{3}{|c|}{ GTAW } & \multicolumn{3}{|c|}{ FCAW § } & \multicolumn{3}{|c|}{ OAWף } & \multicolumn{3}{|c|}{ Other** } \\
\hline & $\mathrm{n}$ & $\%$ & $95 \% \mathrm{Cl}$ & $\mathrm{n}$ & $\%$ & $95 \% \mathrm{Cl}$ & $\mathrm{n}$ & $\%$ & $95 \% \mathrm{Cl}$ & $\mathrm{n}$ & $\%$ & $95 \% \mathrm{Cl}$ & $\mathrm{n}$ & $\%$ & $95 \% \mathrm{Cl}$ & $\mathrm{n}$ & $\%$ & $95 \% \mathrm{Cl}$ \\
\hline Respiratory & 63 & 17.9 & 14.7 to 21.7 & 74 & 21.1 & 18.4 to 25.9 & 39 & 11.1 & 7.5 to 13.0 & 18 & 5.1 & 3.3 to 7.3 & 32 & 9.1 & 6.6 to 11.9 & 35 & 10.0 & 7.5 to 13.0 \\
\hline Flu-like & 61 & 17.4 & 14.7 to 21.7 & 61 & 17.4 & 14.7 to 21.7 & 29 & 8.3 & 6.1 to 11.2 & 14 & 4.0 & 2.5 to 6.1 & 24 & 6.8 & 4.8 to 9.4 & 22 & 6.2 & 4.2 to 8.7 \\
\hline Aches and pains & 42 & 12.0 & 9.3 to 15.2 & 66 & 18.8 & 14.7 to 21.7 & 29 & 8.3 & 6.1 to 11.2 & 10 & 2.8 & 1.5 to 4.7 & 12 & 3.4 & 2.0 to 5.4 & 13 & 3.7 & 2.3 to 5.9 \\
\hline Throat & 89 & 25.4 & 22.2 to 30.1 & 107 & 30.5 & 26.0 to 34.2 & 67 & 19.1 & 16.6 to 23.8 & 38 & 10.8 & 7.5 to 13.0 & 30 & 8.5 & 6.1 to 11.2 & 44 & 12.5 & 9.3 to 15.2 \\
\hline Digestive & 52 & 14.8 & 12.9 to 19.5 & 64 & 18.2 & 14.7 to 21.7 & 34 & 9.7 & 7.3 to 12.8 & 16 & 4.3 & 2.8 to 6.6 & 22 & 6.3 & 4.2 to 8.7 & 20 & 5.7 & 3.9 to 8.2 \\
\hline Taste & 79 & 22.5 & 18.4 to 25.9 & 96 & 27.4 & 24.1 to 32.2 & 48 & 13.7 & 11.08 to 17.4 & 28 & 8.0 & 5.8 to 10.7 & 32 & 9.1 & 6.6 to 11.9 & 36 & 10.3 & 7.5 to 13.0 \\
\hline Fatigue & 51 & 14.5 & 12.9 to 19.5 & 63 & 17.9 & 14.7 to 21.7 & 54 & 15.4 & 12.9 to 19.5 & 22 & 6.3 & 4.2 to 8.7 & 18 & 5.1 & 3.3 to 7.3 & 25 & 7.1 & 4.9 to 9.6 \\
\hline Nasal & 65 & 18.5 & 14.7 to 21.7 & 78 & 22.2 & 18.4 to 25.9 & 42 & 12.0 & 9.3 to 15.2 & 29 & 8.3 & 6.0 to 11.0 & 26 & 7.4 & 5.3 to 10.1 & 35 & 10.0 & 7.5 to 13.0 \\
\hline Ocular & 76 & 21.7 & 18.4 to 25.9 & 95 & 27.1 & 24.1 to 32.2 & 59 & 16.8 & 12.9 to 19.5 & 26 & 7.4 & 5.3 to 10.1 & 26 & 7.4 & 5.3 to 10.1 & 35 & 10.0 & 7.5 to 13.0 \\
\hline
\end{tabular}

*SMAW, shielded metal arc welding; †GMAW, gas metal arc welding; $¥ G T A W$, gas tungsten arc welding; §FCAW, flux cored arc welding; ๆOAW, oxyacetylene welding; **other: various welding and cutting processes like submerged arc welding, oxyacetylene welding, plasma arc welding, oxypropane welding, oxygas cutting, air-carbon arc cutting, oxypropane cutting, and plasma arc cutting.

Table 8 Prevalence of respiratory and systemic symptoms associated with welding on various metals

\begin{tabular}{|c|c|c|c|c|c|c|c|c|c|c|c|c|c|c|c|}
\hline \multirow[b]{3}{*}{ Symptoms } & \multicolumn{15}{|c|}{ Metals } \\
\hline & \multicolumn{3}{|c|}{ Stainless steel } & \multicolumn{3}{|c|}{ Galvanised steel } & \multicolumn{3}{|c|}{ Aluminium } & \multicolumn{3}{|c|}{ Mild steel } & \multicolumn{3}{|c|}{ Other* } \\
\hline & $\mathrm{n}$ & $\%$ & $95 \% \mathrm{Cl}$ & $\mathrm{n}$ & $\%$ & $95 \% \mathrm{Cl}$ & $\mathrm{n}$ & $\%$ & $95 \% \mathrm{Cl}$ & $\mathrm{n}$ & $\%$ & $95 \% \mathrm{Cl}$ & $\mathrm{n}$ & $\%$ & $95 \% \mathrm{Cl}$ \\
\hline Respiratory & 47 & 13.4 & 11.1 to 17.4 & 63 & 17.9 & 14.7 to 21.7 & 32 & 9.1 & 6.6 to 11.9 & 68 & 19.4 & 16.6 to 23.8 & 26 & 7.4 & 5.3 to 10.1 \\
\hline Flu-like & 35 & 10.0 & 7.5 to 13.0 & 72 & 20.5 & 16.6 to 23.8 & 23 & 6.6 & 4.6 to 9.2 & 44 & 12.5 & 9.3 to 15.2 & 15 & 4.3 & 2.8 to 6.6 \\
\hline Aches and pains & 27 & 7.7 & 5.6 to 10.5 & 23 & 6.6 & 4.6 to 9.2 & 13 & 3.7 & 2.3 to 5.9 & 64 & 18.2 & 14.7 to 21.7 & 10 & 2.8 & 1.5 to 4.7 \\
\hline Throat & 75 & 21.4 & 18.4 to 25.9 & 84 & 23.9 & 20.3 to 28.0 & 55 & 15.7 & 12.9 to 19.5 & 108 & 30.8 & 26.0 to 34.2 & 34 & 9.7 & 7.3 to 12.8 \\
\hline Digestive & 30 & 8.5 & 6.3 to 11.4 & 51 & 14.5 & 11.1 to 17.4 & 23 & 6.6 & 4.6 to 9.2 & 54 & 15.4 & 12.9 to 19.5 & 23 & 6.6 & 4.6 to 9.2 \\
\hline Taste & 44 & 12.5 & 9.3 to 15.2 & 96 & 27.4 & 24.1 to 32.2 & 45 & 12.8 & 9.3 to 15.2 & 79 & 22.5 & 18.4 to 25.9 & 27 & 7.7 & 5.6 to 10.5 \\
\hline Fatigue & 54 & 15.4 & 12.9 to 19.5 & 46 & 13.1 & 9.3 to 15.2 & 31 & 8.8 & 6.5 to 11.6 & 72 & 20.5 & 16.6 to 23.8 & 26 & 7.4 & 5.3 to 10.1 \\
\hline Nasal & 57 & 16.2 & 12.9 to 19.5 & 53 & 15.1 & 12.9 to 19.5 & 27 & 7.7 & 5.6 to 10.5 & 81 & 23.1 & 18.4 to 25.9 & 24 & 6.8 & 4.8 to 9.4 \\
\hline Ocular & 57 & 16.2 & 12.9 to 19.5 & 61 & 17.4 & 14.7 to 21.7 & 53 & 15.1 & 12.9 to 19.5 & 100 & 28.5 & 24.1 to 32.2 & 27 & 7.7 & 5.6 to 10.5 \\
\hline
\end{tabular}

*Other: various metals like copper, cast iron, nickel, bronze, lead, pewter, and silver. 
wheezing, cough, and/or chest tightness, was high (14.6\%). This can be partly explained by the exposure conditions of these workers. Indeed, close to $43 \%$ of these welders did not use any sort of respiratory protective equipment. The use of an appropriate respiratory mask equipped with filters was reported by about $26 \%$ of subjects, while about $32 \%$ reported the use of ineffective respiratory protective equipment such as an ordinary paper mask. However, of those wearing an adequate mask only $17.6 \%$ declared using it most of the time. No data were available on the other aspects of working conditions that may also explain the high prevalence of symptoms. Regarding the specific symptoms, welding related wheezing and chest tightness were reported by about $15 \%$ of welders. This is close to earlier findings from a cross sectional survey of 19-27 year old workers who were completing three to nine years of work as shipyard welders; $16 \%$ and $14 \%$ reported welding related wheezing and chest tightness, respectively. ${ }^{14}$ Questionnaires are a good tool for early screening for OA; although the specificity of questionnaires used as a diagnostic tool for OA is low (14\%), its sensitivity is high $(97 \%){ }^{15}$ Although most cross sectional studies using a respiratory questionnaire and/or respiratory function tests have shown that welders are at increased risk of developing respiratory symptoms and bronchial obstruction in comparison with other workers, ${ }^{16}{ }^{17}$ the few longitudinal studies have shown somewhat conflicting findings. One longitudinal study was unable to document the development of respiratory symptoms after five years of exposure, ${ }^{18}$ while another, carried out over a period of seven years, showed a respiratory functional deterioration associated with exposure to welding fumes. ${ }^{19}$

The prevalences of possible MFF (19.7\%) and probable MFF ( $12 \%$ ) found in this study are lower than the $35 \%$ prevalence of MFF found by Kilburn and colleagues ${ }^{6}$ in a cross sectional study of 145 male shipyard welders. This difference could be explained by differences in the definition of MFF. Our definition of MFF was a preliminary attempt to standardise a definition for this common illness in welders. Adopting probable MFF to be the standardised definition is more specific but less sensitive, since welders might experience symptoms suggestive of MFF but not necessarily fever (a requisite for defining probable MFF). Hence, it is suggested that possible MFF be used. A large number of case reports of OA in welders have been published. ${ }^{20-22}$ Malo and Cartier $^{23}$ described two cases of OA in welders exposed to fumes of galvanised metal, as revealed by specific inhalation challenges. One of these two cases developed fever in addition to the late bronchospastic reaction, which might suggest that frequent episodes of MFF could have led to the further development of respiratory problems such as bronchial hyperresponsiveness and OA. Several metals that are low molecular weight compounds have been shown to cause OA associated with the production of specific IgE antibodies against hapten-protein conjugates, suggesting an immunological mechanism for the development of OA. ${ }^{15}$ Both immunological and nonimmunological factors contribute to the pathogenesis of metal induced OA. IgE mediated mechanisms have been shown in nickel, chromium, cobalt, and platinum induced asthma. ${ }^{15}$ Nevertheless, the issue remains as to whether MFF may be a marker of respiratory symptoms, suggestive of OA, as caused by exposure to welding fumes.

This study did not detect any significant difference between smokers, ex-smokers, and non-smokers with respect to the index of welding related respiratory symptoms, possible MFF, or probable MFF. This finding is in accordance with results from a study carried out by Kilburn and colleagues, ${ }^{6}$ showing that the frequency of respiratory and systemic symptoms was not different for welders who were current smokers than for non-smoking welders.

Experimental exposure of humans to zinc metal fumes can result in the release of cytokines, which can partly explain the fever component of MFF. ${ }^{24}$ With regard to the toxicity of the welding fumes, in vitro cytotoxicity studies showed that weld- ing of stainless steel generates the most toxic fumes, and that particles from the shielded metal arc welding process (SMAW) on stainless steel were far more toxic than those from gas metal arc welding (GMAW) on stainless steel. ${ }^{25}{ }^{26}$ Both Stern and co-workers ${ }^{25}$ and Hooftman and co-workers ${ }^{26}$ reported that the observed cytotoxic effects are largely due to the soluble chromium content generated in particular by SMAW on stainless steel. On the other hand, Kilburn and colleagues ${ }^{6}$ found that MFF symptoms were significantly more prevalent in aluminium welders than in those who welded stainless steel or mild steel. The interpretation of this finding was that aluminium welders were most symptomatic because they used the GMAW process, which produces fewer fumes but more ozone than does SMAW on steel. This survey showed, in accordance with the literature, that galvanised steel was mostly associated with the presence of symptoms suggestive of MFF. However, as suggested by this survey, exposure to mild steel welding fumes constitutes a respiratory hazard that might have been previously underestimated. Recently, an increased risk of asthma among welders has been observed in some epidemiological studies, ${ }^{27} 28$ supporting a relation between stainless steel welding and OA, and also suggesting that mild steel welding may indeed be a potential cause of OA. This has been documented in one interesting case report of occupational asthma due to GMAW on mild steel. ${ }^{21}$

The current cross sectional study has several limitations. First, this is not a survey with a probabilistic sampling and representativity cannot be determined. Although the associations we report are likely valid, their generalisability to all welders is uncertain. Second, recall problems might have affected reporting. The healthy worker effect also seems to be an issue: as shown in table 5, employment as a welder for 20-29 years proved to be a protective factor against the development of wheezing. As with any other cross sectional study, the issue of temporality is always a restriction. Here, this issue is exemplified by the instance where both systemic and respiratory symptoms took place; one cannot be certain which type of symptom occurred first, leading to the manifestation of other symptoms. As such, there is a need to undertake a more elaborate longitudinal study, especially as this study showed a rather high prevalence of respiratory and systemic symptoms due to exposure to welding fumes in which baseline host factors could be examined.

Furthermore, the issue of not having an external comparison group in this survey might be seen as a constraint for attributing the occurrence of symptoms to exposure to welding fumes. However, as revealed by earlier studies, welders always showed a higher prevalence of systemic symptoms than did non-welders ${ }^{6}$ : episodes of fever, chills, fatigue, muscle aches, thirst, and metallic taste were reported by over $35 \%$ of welders, while none of the non-welders experienced MFF. In that same study, smoking welders (28.6\%), ex-smoking welders $(26.3 \%)$, and non-smoking welders $(37.0 \%)$ reported experiencing more symptoms of either fatigue, muscle aches, or metallic taste than did current smoking and non-smoking non-welders (17\%). ${ }^{6}$

In conclusion, this study showed a high prevalence of the co-occurrence of welding related respiratory and systemic symptoms. It also showed an association between MFF and respiratory symptoms suggestive of occupational asthma. We hypothesise that MFF might be an interesting pre-marker of respiratory symptoms suggestive of OA caused by exposure to welding fumes, as MFF occurs shortly following exposure, while welding related respiratory symptoms take longer to occur. A prospective study is needed to verify this hypothesis.

\section{ACKNOWLEDGEMENTS}

The authors express their appreciation for the coordinating efforts of Marcelle Petitclerc, who contacted the welders by mailing them an information letter describing their role in the survey. They also thank 
Danielle LeClerc for conducting the interviews, Heberto Ghezzo, PhD for his statistical opinion with regard to data analysis, and Margaret Becklake, PhD for her opinion in defining MFF. They are also thankful to the welders who took part in the survey. They acknowledge the personnel from "Direction Santé Publique" Montréal-Centre and Laval for furnishing the list of welders. Finally, the authors thank Lori Schubert for revising the manuscript.

\section{Authors' affiliations}

M El-Zein, C Infante-Rivard, Joint Departments of Epidemiology and Biostatistics and Occupational Health, McGill University, Montréal, Canada

J-L Malo, D Gautrin, The Department of Chest Medicine, Hôpital du Sacré-Coeur, Montréal, Canada

Supported by the Quebec Lung Association and Le Fonds de la Recherche en Santé du Québec (FRSQ). Mariam El-Zein is a PhD student funded by the Max-Stern Recruitment Fellowship, McGill University.

Denyse Gautrin is a research scholar with the FRSQ

\section{REFERENCES}

1 Groth $M$, Lyngenbo O. Respiratory symptoms in Danish welders. Scand J Soc Med 1989;17:271-6.

2 Cotes JE, El-Gamal FM. Cardio-respiratory associations with shipyard welding and burning. In: Stern RM, Berlin A, Fletcher AC, Jarvisalo J, eds. Health hazards and biological effects of welding fumes and gases. Excerpta Medica, 1985

3 Gordon T, Fine J. Metal fume fever. Occup Med 1993;8:505-17.

4 Sferlazza SJ, Beckett WS. The respiratory health of welders. Am Rev Respir Dis 1991;143(5 Pt 1):1134-48.

5 Offermann PV, Finley CJ. Metal fume fever. Ann Emerg Med 1992;21:872-5.

6 Kilburn KH, Warshaw RH, Boylen CT, et al. Respiratory symptoms and functional impairment from acute (cross-shift) exposure to welding gases and fumes. Am J Med Sci 1989;298:314-19.

7 Burney $\mathbf{P}$, Laitinen L, Perdrizet S, et al. Validity and repeatability of the IUATLD (1984) bronchial symptom questionnaire: an international comparison. Eur Respir J 1989;2:940-5.

8 Menzies R, Tamblyn R, Farant JP, et al. The effect of varying levels of outdoor-air supply on the symptoms of sick building syndrome. N Engl J Med 1993;328:821-7

9 Ryon DLS, Rom WN. Diseases caused by respirartory irritants and toxic chemicals. In: Stellman JM, ed. ILO encyclopedia of occupational health and safety. Geneva: ILO, 1997:12-18.
10 Malo JL, Malo J, Cartier A, et al. Acute lung reaction due to zinc inhalation. Eur Respir J 1990;3:111-14.

11 Nemery B, Demedts M. Respiratory involvement in metal fume fever. Eur Respir J 1991:4:764-5.

12 Vogelmeier C, Konig G, Bencze K, et al. Pulmonary involvement in zinc fume fever. Chest 1987;92:946-8.

13 Bernstein I, Nemery B, Brooks S. Metals. In: Bernstein I, Chan-Yeung M Malo J-L, Bernstein D, eds. Asthma in the workplace. New-York: Marcel Dekker, 1999:501-21.

14 Beach JR, Dennis JH, Avery AJ, et al. An epidemiologic investigation of asthma in welders. Am J Respir Crit Care Med 1996;154:1394-400.

15 Vandenplas O, Binard Van-Cangh F, Brumagne A, et al. Occupational asthma in symptomatic workers exposed to natural rubber latex: evaluation of diagnostic procedures. J Allergy Clin Immunol 2001;107:542-7.

16 Lyngenbo O, Groth S, Groth M, et al. Occupational lung function impairment in never-smoking Danish welders. Scand J Soc Med 1989;17:157-64

17 Rastogi SK, Gupta BN, Husain T, et al. Spirometric abnormalities among welders. Environ Res 1991;56:15-24.

18 Mur J, Pham Q, Teculescu D, et al. Arc welders' respiratory health evolution over five years. Intern Arch Occup Environ Health 1989:61:321-7.

19 Chinn DJ, Stevenson IC, Cotes JE. Longitudinal respiratory survey of shipyard workers: effects of trade and atopic status. Br J Ind Med 1990:47:83-90.

20 Khoo GT. Occupational asthma from welding: a case report. Ann Acad Med Singapore 1996;25:293-5.

21 Vandenplas O, Dargent F, Auverdin JJ, et al. Occupational asthma due to gas metal arc welding on mild steel. Thorax 1995;50:587-8.

22 Vandenplas O, Delwiche JP, Vanbilsen ML, et al. Occupational asthma caused by aluminium welding. Eur Respir J 1998;11:1182-4.

23 Malo JL, Cartier A. Occupational asthma due to fumes of galvanized metal. Chest 1987:92:375-7.

24 Blanc $\mathbf{P}$, Wong $\mathrm{H}$, Bernstein MS, et al. An experimental human model of metal fume fever. Ann Intern Med 1991;114:930-6.

25 Stern RM, Hansen K, Madsen AF, et al. In vitro toxicity of welding fumes and their constituents. Environ Res 1988:46:168-80.

26 Hooftman RN, Arkesteyn CW, Roza P. Cytotoxicity of some types of welding fume particles to bovine alveolar macrophages. Ann Occup Hyg 1988;32:95-102.

27 Toren K, Jarvholm B, Brisman J, et al. Adult-onset asthma and occupational exposures. Scand J Work Environ Health 1999;25:430-5.

28 Toren K, Balder B, Brisman J, et al. The risk of asthma in relation to occupational exposures: a case-control study from a Swedish city. Eur Respir J 1999;13:496-501.

\section{Genetic make up and external stimuli interact to cause lung disease}

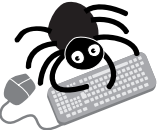

Please visit the Occupational and

Environmental website [www.occenvmed. com] for link to this full article. prospective epidemiological study in coal miners is the first to suggest that genetic
background and environmental oxidative stimuli interact to influence development of
pneumoconiosis. Tumour necrosis factor $\alpha$ (TNF) -308 genotype affected glutathione peroxidase (GSH-Px) and catalase activities in red blood cells. Genotypes with homozygous 22, heterozygous 12 alleles significantly reduced GSH-Px activity and increased catalase activity. Lymphotoxin $\alpha$ (LTA) NcoI genotype seemed to have no effect.

TNF-308 genotype and exposure to environmental oxidants together influenced GSH-Px activity under oxidative stress with cumulative occupational dust exposure but not with cigarette smoking. TNF-308 22, 12 genotypes had significantly reduced GSH-Px activity with high dust exposure ( $>71 \mathrm{mg} / \mathrm{m}^{3} /$ year $)$ and 2.5 times higher five year incidence of pneumoconiosis than with low exposure. LTA NcoI genotype interacted with catalase activity on the incidence of pneumoconiosis. Low catalase activity ( $\leqslant 107 \mathrm{k} / \mathrm{g} \mathrm{Hb})$ and LTA NcoI 22 genotype resulted in significantly higher disease incidence than high catalase activity and 11, 12 genotypes.

There was no direct relation between TNF-308 genotypes and cumulative dust exposure or disease incidence, but a borderline relation for LTA NcoI 11, 12 genotypes and significant relation between genotype 22 and disease severity. Age, BMI, smoking, and current exposure to coal dust were unrelated to genotypes $11,12,22$ of both genes.

Genetic differences may underlie conflicting reports about individuals' responses to environmental oxidants. This study tested the hypothesis that gene polymorphisms in two prominent proinflammatory molecules in lung disease influence oxidative responses in 253 coal miners variously exposed to cigarette smoke and coal dust.

\ Journal of Medical Genetics 2003;40:96-103. 